\title{
Effects of Sleep Debt on Cognitive Performance and Prefrontal Activity in Humans
}

\author{
Kenichi Kuriyama and Motoyasu Honma \\ Department of Adult Mental Health, \\ National Institute of Mental Health, \\ National Center of Neurology and Psychiatry \\ Japan
}

\section{Introduction}

Functional neuroimaging is universally recognized to be a remarkably effective modality for exploring precise brain function. Functional magnetic resonance imaging (fMRI) and positron-emission tomography (PET) are among the most widely used neuroimaging techniques; however, their invasiveness in terms of, for example, exposure to high magnetic fields or radiation, or restriction of body movement during the examination, makes their application difficult in infants, children, and some subjects with an atypical condition.

Near infrared spectroscopy (NIRS), on the other hand, is an alternative neuroimaging modality that is suitable for use with most individuals due to its non-invasive nature. It measures local cortical activity during brain activation. Although NIRS has several limitations compared with fMRI and PET, it is an appropriate and feasible method to use with infants, children, and other subjects such as those who suffer from loss of sleep. Naturally, sleep loss raises some problems related to the subject keeping still yet awake during the examination, but otherwise is a good option. The effects of sleep loss on local cortical activities associated with certain cognitive functioning as assessed by NIRS are the topic of this chapter.

\section{Utilization of NIRS for functional brain imaging}

Information processing in the brain occurs via two different systems, a neuroelectric transmission system and an energy-supplying system to neurons (Guiou et al., 2005). Nutrient arteries around the neurons supply them with blood containing the oxygen and glucose necessary for neural activity. Thus, changes in the ratio of oxygenated hemoglobin (oxy- $\mathrm{Hb})$ to deoxygenated hemoglobin (deoxy-Hb) due to increased blood flow for such activity should be observable in tissues adjacent to the activated neurons. This relationship between neural activity and subsequent changes in cerebral blood flow is known as neurovascular coupling (Guiou et al., 2005; Rasmussen et al., 2009).

Similar to fMRI and PET, NIRS indirectly measures local cortical activity in vivo by measuring the differential concentration between oxy- and deoxy- $\mathrm{Hb}$ in the blood vessels. Specifically, it measures the difference in the absorption rate of near-infrared light by oxy- 
and deoxy- $\mathrm{Hb}$, and the scalp and skull are high permeable to near-infrared light (Obrig et al., 2000). When such light is locally irradiated from an irradiation probe, it diffuses in the cerebral tissue up to a depth of $20-30 \mathrm{~mm}$. A detection probe located $30 \mathrm{~mm}$ from the irradiation probe can detect the light diffusely reflected by the oxy- or deoxy-Hb, making it possible to estimate local changes in oxy-, deoxy- and total-Hb concentrations (Ferrari et al., 2004). For high-resolution detection of oxy- and deoxy-Hb concentrations, multiple channels of wavelengths (2 or 3) of near-infrared light $(700-1000 \mathrm{~nm})$ are usually simultaneously irradiated and detected.

NIRS has been widely used for several years in medical and biological studies of the brain. Although NIRS uses an accessible, non-invasive neuroimaging device, it should be applied to measure local cerebral metabolic rate of oxygen consumption with consideration given to its strong and weak points, which are listed in Table 1.

\section{Strengths (compared with MRI or PET)}

- inexpensive

- high portability

- easy-to-use approach

- $\quad$ high tolerance to body movements

- high temporal resolution (10 $\mathrm{Hz}$ or less)

- high tolerance to long-time measurements

- utility regardless of subject's posture

- independence of a specific measurement setting

Weaknesses (compared with MRI or PET)

- low spatial resolution

- difficulty in strict identification of anatomic locations

- narrow range of measurement (only cortical surface)

- relative quantitation (not absolute quantitation)

Table 1. Strengths and weaknesses of NIRS

\section{Effects of sleep loss on cognition}

Although what constitutes sufficient quality and quantity of sleep per day remains a subject of debate due to its the wide interindividual variability and age-related differences, it has been elucidated that sleep loss deteriorates various cognitive functions, whether due to partial or total sleep deprivation and chronic or acute sleep disturbance. Loss of sleep also impairs the activities of various cerebral regions or neural networks associated with ongoing cognitive performance. A recent study in rats suggested that sleep loss often elicits periods of local sleep, in which some neurons often go 'offline' briefly in one cortical area but not in another during long periods of wakefulness (Vyazovskiy, 2011). Several basic cognitive functions are vulnerable to sleep loss in humans. These include simple response speed (Buysse et al., 2005; Frey et al., 2004; Koslowsky \& Babkoff, 1992), psychomotor vigilance (Blatter et al., 2005; Doran et al., 2001; Drake et al., 2001; Van Dongen et al., 2003), mental arithmetic (Frey et al., 2004; Stenuit \& Kerkhofs, 2008; Van Dongen et al., 2003;), response inhibition (Drummond et al., 2006; Stenuit \& Kerkhofs, 2008), problem solving (Killgore et al., 2008; Nilsson et al., 2005), and short-time perception (Soshi et al., 2010). However, the 
performance of executive functions, one of the higher cognitive functions that includes divided attention (Drake et al., 2001; Frey et al., 2004; Lim \& Dings, 2010; Stenuit \& Kerkhofs, 2008) and working memory (Bartel et al., 2004; Binks et al., 1999; Choo et al., 2005; Frey et al., 2004; Lim \& Dings, 2010; Tucker et al., 2010; Wimmer et al., 1992) varies among studies; some report a significant effect of sleep loss (Bartel et al., 2004; Choo et al., 2005; Drake et al., 2001; Frey et al., 2004; Stenuit \& Kerkhofs, 2008), while others report no such effect (Binks et al., 1999; Lim \& Dings, 2010; Tucker et al., 2010; Wimmer et al., 1992).A discrepancy has also been seen in the influence of sleep loss has on behavioral performance versus its influence on neural activity; functional neuroimaging has revealed that sleep loss deteriorates not behavioral performance but neural activity (Choo et al., 2005). Such a discrepancy could point to a difference in neural substrates between basic and higher cognitive functions and/or possible personal differences in vulnerability of executive functions to sleep loss. We describe here two of our studies conducted using NIRS in order to explore the influence of sleep loss on basic and higher cognition associated with the frontal functions mentioned above.

\section{Influence of sleep loss due to total deprivation of a night's sleep on time perception}

\subsection{Short-time perception}

When elapsed time is comparatively brief (within several minutes), humans can typically perceive the passage of time accurately without referring to an artificial time keeping device such as a wristwatch (Ivry, 1996; Rammsayer, 1999; Treisman, 1963). Human short-time perception is modulated by a robust neural basis consisting of subcortical structures, such as the cerebellum and basal ganglia, together with the right prefrontal cortex (Harrington et al., 1998; Pouthas et al., 1999). Moreover, a circadian pacemaker located in the suprachiasmatic nucleus of the hypothalamus, which is driven by a self-sustaining oscillator with a period of about $24 \mathrm{~h}$ and provides the time of day, participates in short-time perception (Aschoff, 1998; Ashoff \& Daan, 1997; Kuriyama et al., 2003). As such, short-time perception is not independent of the influence of the circadian pacemaker; under a condition where zeitgebers are strictly controlled, short-time perception fluctuates on around a 24-h cycle and correlates with circadian markers such as core body temperature and melatonin, and consequently shows diurnal variation (Kuriyama et al., 2005). It has been confirmed that short-time perception shortens from morning into night, and is prolonged again from night to the next morning under a 30-h constant routine (Kuriyama et al., 2005; see Fig. 1). For sleep deprivation on the other hand, it has been reported that there is less diurnal variation
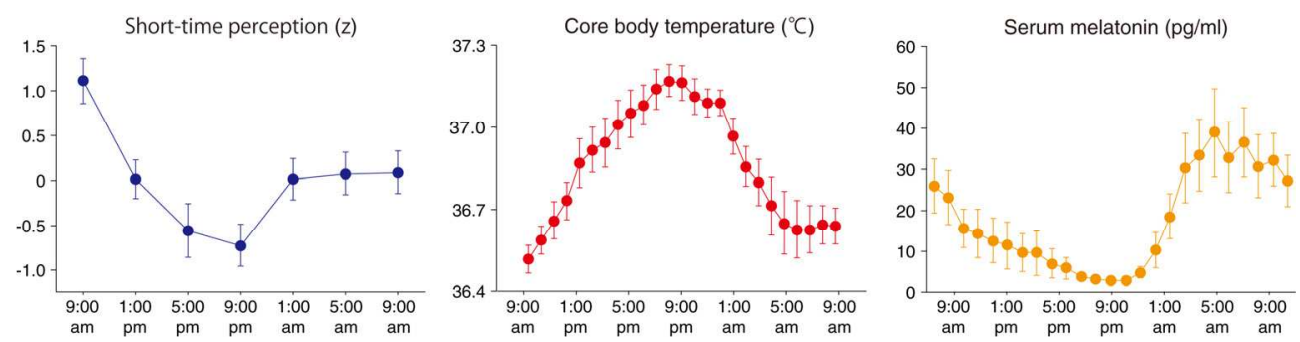

Fig. 1. Diurnal fluctuation of short-time perception 
in short-time perception as it is dissociated from endogenous circadian markers (Kuriyama et al., 2005; Soshi et al., 2010). This may be because short-time perception is modulated by the prefrontal cortex (PFC) along with subcortical structures including the circadian pacemaker; it is well known that the PFC is vulnerable to sleep loss, and this vulnerability presumably disturbs short-time perception (Soshi et al., 2010). To elucidate this issue, Soshi et al. (2010) utilized NIRS because it neither produces pulse scanning noise nor requires severe restriction of the subject's body posture nor movements, and thus is unlikely to seriously influence the sleep-deprived condition. It is also suitable for monitoring the subject's condition while performing the experimental tasks.

\subsection{Study design}

Fourteen healthy male university students participated in a crossover design study conducted over a 4-day period. Subjects performed a 10-s time production (TP) task in sleep controlled (SC) and sleep deprived (SD) conditions, scheduled in random order with a 1-day interval (Fig. 4). On the first day (day 1) NIRS probes were attached to the surface of the scalp. The 15-min TP session in either the SC or SD condition started at 21:00. After the session, in the SC condition, subjects rested without sleep or exercise until 0:00 and then stayed in bed under complete darkness (> 0.1 lux) until 08:00 on day 2; in the SD condition, subjects stayed awake quietly under room light (100 lux) until 08:00 the next morning while being monitored by video. On day 2, the TP session started again at 09:00. All the experiments were performed at a time isolation facility, and the ambient temperature and humidity were maintained constant throughout the study.

TP tasks were arranged in an event-related design to detect the hemodynamic response for a single trial. TP sessions were conducted at 21:00 on day 1 and 09:00 on day 2, corresponding to the expected nadir and peak period of the diurnal variation of TP in subjects with a regular sleep-wake cycle. Each TP session consisted of 15 trials with 30-s inter-trial intervals. Subjects were asked to produce a 10-s interval and to begin and end each trial by pressing a key button (Kuriyama et al., 2003, 2005). Duration from the first to the second button presses was defined as the perceived time.

\subsection{NIRS recording and data analysis}

Regional hemodynamic changes in brain tissue were monitored throughout the TP sessions by a continuous wave-type NIRS system (FOIRE-3000; Shimazu Co., Tokyo, Japan; Fig. 2) which outputs near-infrared light at three wavelengths (780, 805 and $830 \mathrm{~nm}$ ). All transmitted intensities of the three wavelengths were recorded every $130 \mathrm{~ms}$ at 22 channels in order to estimate concentration changes in oxy- $\mathrm{Hb}$, deoxy- $\mathrm{Hb}$, and total- $\mathrm{Hb}$, based on the modified Beer-Lambert equation as a function of light absorbance of $\mathrm{Hb}$ and pathlength. A set of $3 \times 5$ probes were utilized, in which light detectors and emitters were alternately positioned at an equal distance of $30 \mathrm{~mm}$. The 22 channels (see Fig. 3) covered the middle and superior PFC regions (BA9, 46, 10).

$\mathrm{Oxy}-\mathrm{Hb}$ data was chosen to examine event-related responses in the PFC since it is an optimal index for changes in regional cerebral blood flow (Hoshi et al., 2001). We applied a high-pass filter to raw data, re-sampled at $10 \mathrm{~Hz}$, using a low-cutoff frequency of $0.05 \mathrm{~Hz}$. Smoothing was performed by the moving average method (boxcar filter) with a sliding time 


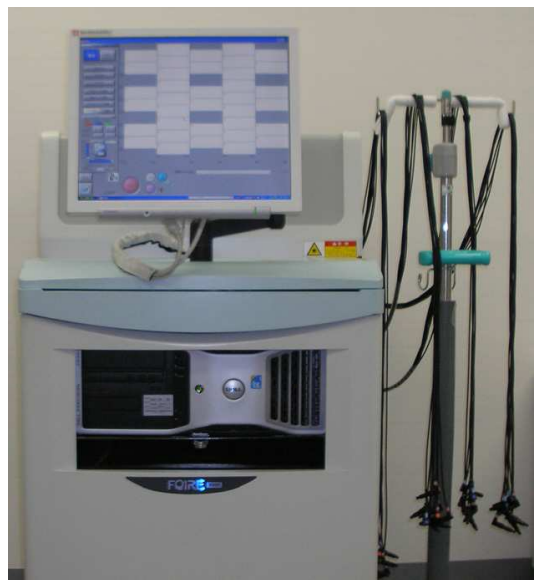

Fig. 2. NIRStation FOIRE-3000 (Shimazu Co., Tokyo, Japan)

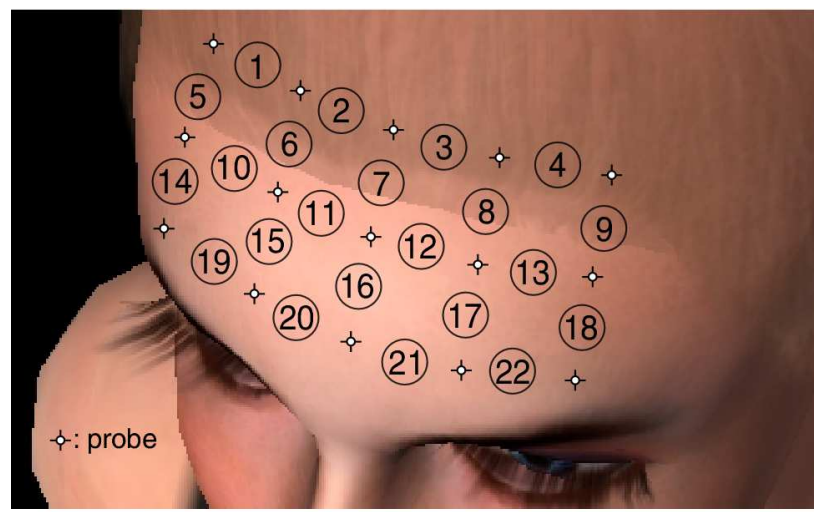

Fig. 3. Schematic layout of NIRS probes with recorded channels on the frontal region

window of $1.1 \mathrm{~s}$. Data were normalized into z-scores to avoid the methodological ambiguity that changes in absolute values of $\mathrm{Hb}$ concentration for each recording channel would not be determined because the absolute path lengths of light through the cerebral cortex were not detectable. Concentration changes time-locked to trial onset were extracted from $5 \mathrm{~s}$ before to $27 \mathrm{~s}$ after the onset, covering a mean produced time of around $11 \mathrm{~s}$ and a mean rest interval of around $16 \mathrm{~s}$. A total of 15 epochs were obtained for each experimental day (day 1 or day 2) in each condition (SC or SD). Before individual averaging, baselines were corrected with mean z-scores of $5 \mathrm{~s}$ before trial onset. Grand averaged concentration changes in the left anterior PFC (LAPFC) region, based on statistical analyses, were superimposed.

\subsection{Effects of sleep loss on short-time perception}

Behavioral data suggested that time perception fluctuates through the night to the morning in the SC condition; TP was significantly prolonged from night to the next morning. However, TP was not prolonged from night to the next morning in the SD condition (Fig. 4). 


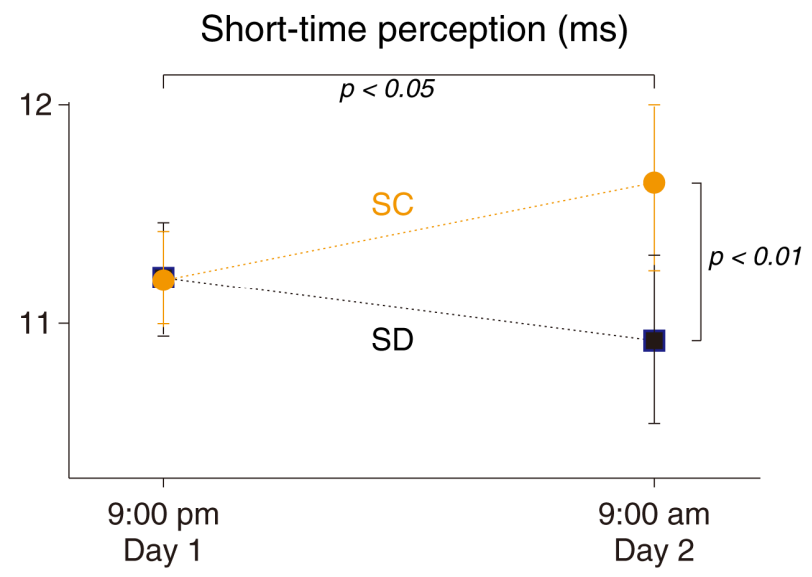

Fig. 4. Sleep deprivation attenuates short-time perception the following morning

It was previously shown that a short-time perception profile exhibits diurnal variation, reaching a peak (the longest produced time) around 09:00 and a nadir (the shortest produced time) around 21:00 with a regular sleep-wake cycle under experimental conditions (Kuriyama et al., 2005). Taken together, circadian oscillation in short-time perception under the SD condition is clearly attenuated.

\subsection{Influence of the PFC's vulnerability to sleep loss on short-time perception}

$\mathrm{Oxy}-\mathrm{Hb}$ concentration measured by NIRS suggested that PFC activity in the SD condition, compared with that in the SC condition, was more enhanced in the left hemisphere on day 2. Moreover, enhanced oxy- $\mathrm{Hb}$ concentration changes on day 2 in the SD condition, compared with those in the SC condition, were observed in the LAPFC region of interest (ROI) at channels 17, 21, and 22 (Fig. 5).

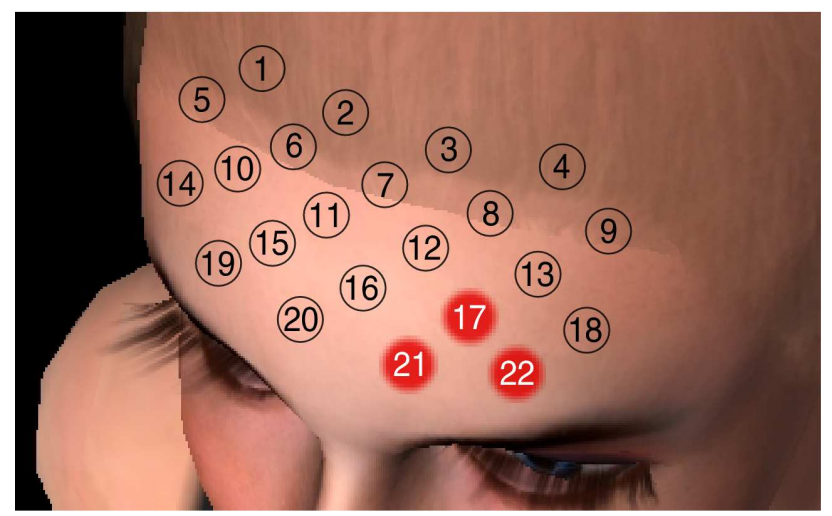

Fig. 5. Left anterior PFC activity during the TP task was enhanced after sleep deprivation

A functional correlation was observed between increased activation of the LAPFC after sleep deprivation and short-time perception, although unlike in previous studies 
(Harrington et al., 1998; Pouthas et al., 1999) the present study failed to detect any significant changes in right PFC activity (Soshi et al., 2010). It has also been argued that increased activation of the PFC after sleep deprivation is associated with neural compensation for cognitive function, although TP on day 2 in the SD condition was different from that in the SC condition.

NIRS has a serious shortcoming in that it cannot determine whether or not a subcortical network including the cerebellum and the basal ganglia contributes to attenuating the diurnal fluctuation of short-time perception. If subcortical activities may be altered by sleep deprivation, attenuation of short-time perception possibly reflects subcortical vulnerability, and thus the PFC activity change is possibly only a byproduct.

A temporary decline in the diurnal variation of short-time perception may be important for surviving a crisis, such as in an emergency situation. Time perception in humans should be fundamentally synchronized to the physical state to allow for constant adaptation to the regularity of daily life; however, in times of severe stress, time perception must desynchronize from regular physical homeostasis and be shortened, to enable time expansion and presumably allow us to adopt suitable strategies for coping with the stressful environment by thinking and acting more rapidly than usual. In-depth consideration of the adaptive nature of the PFC function in humans (Duncan, 2001; Miller \& Cohen, 2001) suggests that the PFC might play a switch-like role in short-time perception as a situation demands, helping us meet demands for adaptation.

\section{Influence of sleep loss due to partial deprivation of a night's sleep on individual differences in working memory performance}

\subsection{Working memory performance}

As already noted in Section 3 concerning the effects of sleep loss on cognition, a discrepancy in the effects that sleep loss has on behavioral performance compared with the effects it has on neural activity has been reported in relation to working memory performance; sleep loss does not deteriorate behavioral performance itself, but rather the neural activity associated with the behavior. Possible interindividual differences in the vulnerability to sleep loss of executive functions, which also play crucial roles in working memory processing, have also been suggested. We explored this issue in a second study using NIRS (Honma et al., 2010).

\subsection{Study design}

Fifty-five healthy university students (26 males, 29 females) participated in the study. Subjects, who regularly slept 7-9 h in a night, participated in an overnight experiment in a laboratory setting, starting at 22:00 on day 1 and finishing at 10:00 on day 2. Subjects were deprived an average of $2.32 \mathrm{~h}(29.5 \%)$ of sleep by experimental manipulation. Subjects retired to bed at 01:00 in the laboratory and were forcibly awakened at 07:00 am.

A visual n-back working memory (WM) task (Callicott et al., 1998, 1999; Gevins \& Cutillo, 1993; Kuriyama et al., 2008) with two separate load levels was utilized. For the 0-back task (low-load WM task), subjects had to respond whenever a single-digit number appeared on a screen. For the 2-back task (high-load WM task), they had to press a button on the right when the single-digit number on the screen was identical to that which had appeared last 
but one, otherwise to press the button on the left. Each level of task was run in blocks of $12+n$ stimuli and was conducted two times; thus, 24 responses were obtained at each load level. Average response times (RTs) and correct response rates (\%CRs) were evaluated.

Alertness level was evaluated immediately before and after the experiment using the Stanford Sleepiness Scale (SSS; Hoddes et al., 1971). The SSS consists of a 7-point scale ranging from level 1 (feeling active, vital, alert, or wide awake) to level 7 (no longer fighting sleep). Subjects selected the most appropriate level to reflect their present state of alertness. To assess individual ability to overcome sleepiness during WM tasks, change in SSS level was individually calculated by subtracting the post-experiment SSS score from the preexperiment SSS score.

\subsection{NIRS recording and data analysis}

Regional hemodynamic changes in brain tissue were monitored throughout the TP sessions by a continuous wave-type NIRS system (ETG-100, Hitachi Medical Co., Tokyo, Japan: Fig. 6), which outputs near-infrared light at two wavelengths (780 and $830 \mathrm{~nm}$ ). Oxy- and deoxy$\mathrm{Hb}$ concentrations were measured in a manner similar to the short-time perception study (Soshi et al., 2010) described in the preceding section [section 4.3].

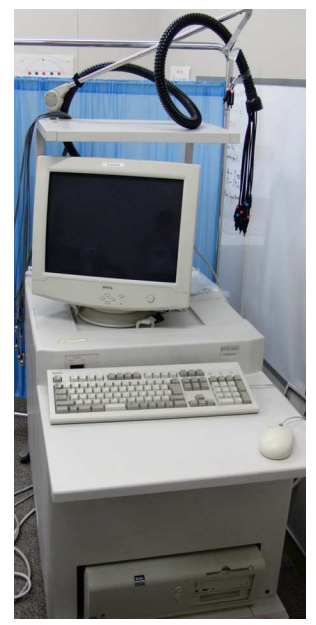

Fig. 6. Optical Topography System ETG-100 (Hitachi Medical Co., Tokyo, Japan)

We analyzed oxy- $\mathrm{Hb}$ data as a reflection of event-related responses in the PFC. The continuous oxy- $\mathrm{Hb}$ data were filtered with band-pass frequencies in the range of $0.01-0.2$ $\mathrm{Hz}$ and were standardized (z-score). Changes in oxy-Hb concentration time-locked to experimental blocks consisting of 12 trials were extracted for each experimental condition $1000 \mathrm{~ms}$ before the onset of the trial block (baseline) to $4400 \mathrm{~ms}$ after the onset $(2400 \mathrm{~ms}$ for the 12-trial duration and $2000 \mathrm{~ms}$ for the post-trial interval). Baseline correction of the changes in oxy- $\mathrm{Hb}$ concentration was performed utilizing the mean z-scores of $1000 \mathrm{~ms}$ prior to the onset of the experimental blocks before individual averaging. Mean z-scores of the changes in oxy- $\mathrm{Hb}$ concentration during the $4400 \mathrm{~ms}$ period after the beginning of the trial block were utilized for subsequent statistical analysis. 


\subsection{Influence of the PFC's vulnerability to sleep loss on working memory performance}

Twelve of the 55 subjects showed overnight decrements in alertness level as reflected by an increased SSS level (average: 1.41, SD: 0.41), while conversely 17 showed overnight decrements reflected by a decreased SSS level (average: 21.29, SD: 0.49), and 26 showed no change in alertness level. The change in alertness level was negatively correlated with RT on the 2-back task, but not on the 0-back task (Fig. 7), and the change in SSS was not correlated with \%CR regardless of the task difficulty.

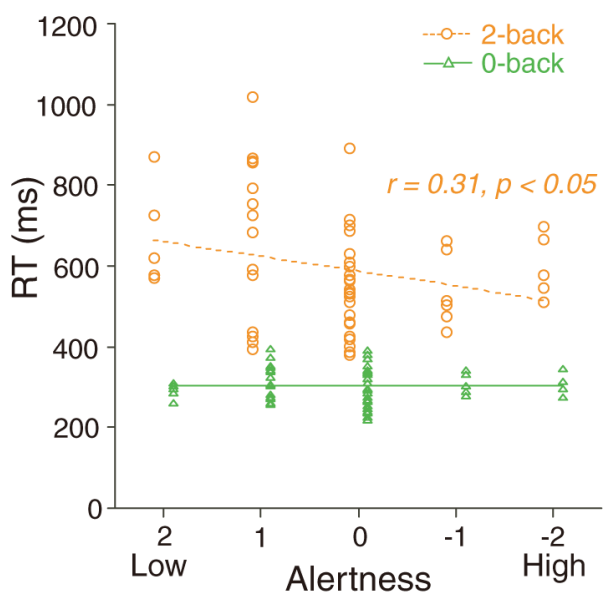

Fig. 7. Correlation of overnight change in alertness level with that in WM performance

Although the subjects had similar sleep-wake habits in daily life and they experienced the same restricted sleep duration on the experimental night, alertness was increased in some subjects but was decreased in others during the WM tasks. This suggests that subjects who improved their alertness - who may have better abilities to overcome sleepiness - showed better performance not on the low-load WM task but on the high-load WM task.

\subsection{Relationship between the PFC's vulnerability to sleep loss and working memory processing difficulties}

At every channel in the bilateral PFC region, differences in the change in oxy- $\mathrm{Hb}$ concentration between the 2- and 0-back tasks positively correlated with overnight change in alertness (Fig. 8), which is in line with previous neuroimaging studies using fMRI (Cohen et al., 1997; Owen et al., 1998) and PET (Owen et al., 1996; Sweeney et al., 1996). On the other hand, change in oxy- $\mathrm{Hb}$ concentration in the bilateral PFC region on the 2-back task for some channels (channels 5, 10,13, and 18) positively correlated with overnight change in alertness (Fig. 9 left), while change on the 0-back task for some channels (channels 10 and 15) in the right PFC region negatively correlated with overnight change in alertness (Fig. 9 right).

The activity in the right prefrontal site corresponding to channel 10 showed an opposite pattern between the 2- and 0-back tasks (Fig. 10), suggesting the ability to conquer sleepiness. This ability might contribute to the function of providing sufficient activity to 


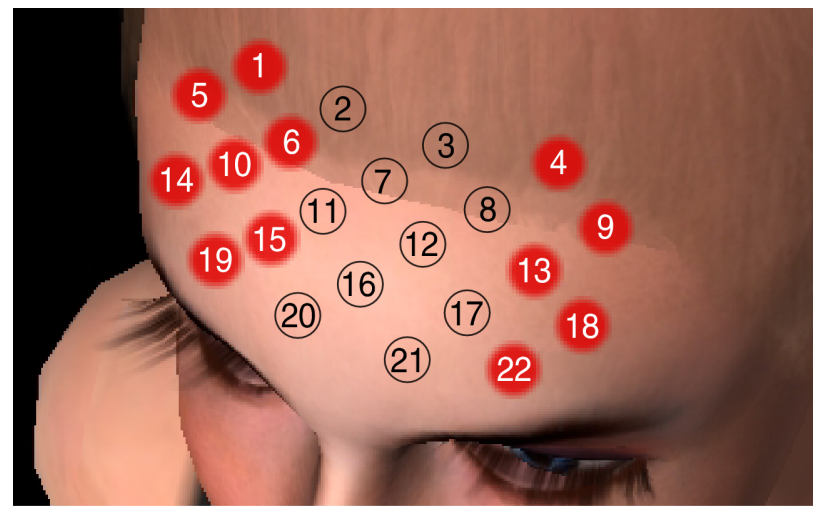

Fig. 8. Significant positive correlation between changes in oxy-Hb concentration and alertness for the difference between the 2- and 0-back tasks

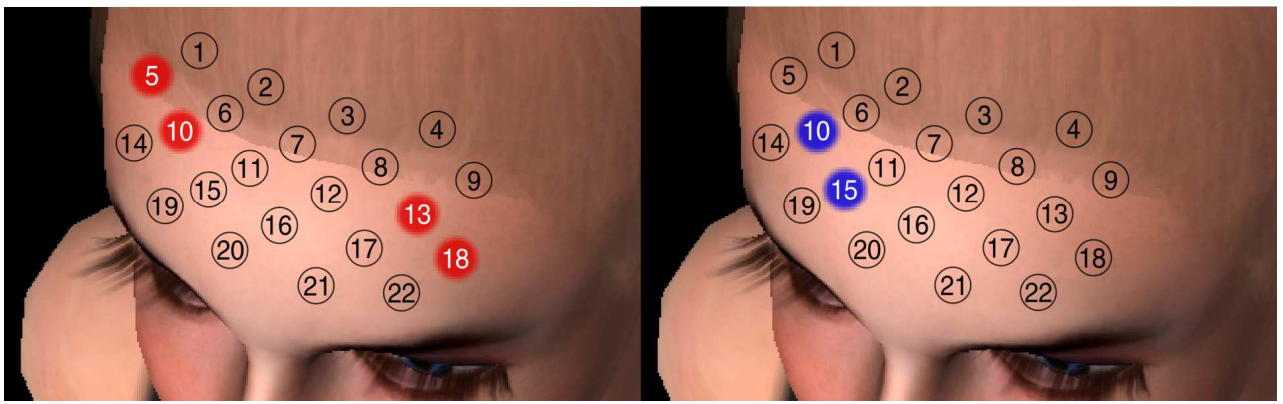

Fig. 9. Correlation between changes in oxy-Hb concentration and alertness on the 2-back task (left panel) and 0-back task (right panel)

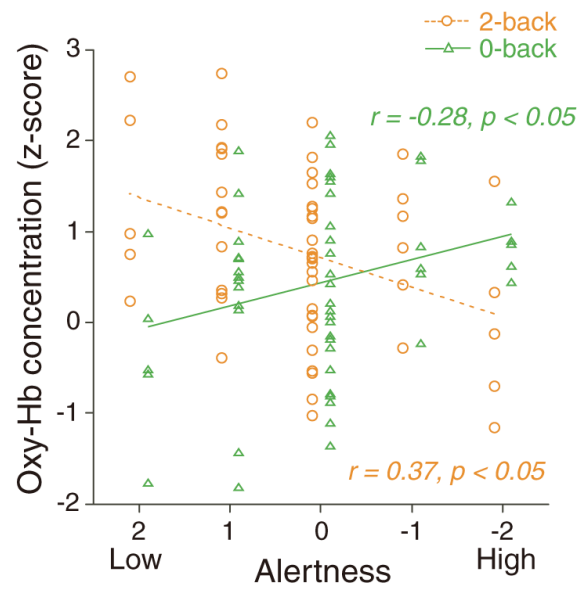

Fig. 10. Correlation between changes in oxy- $\mathrm{Hb}$ concentration and alertness on the 2- and 0back tasks for channel 10 
match the demands of a task. In other words, the cortical activity corresponding to channel 10 susceptibly escalates with changes in both alertness and cognitive load, thereby achieving better performance. This site in the right PFC might therefore be related to the ability to conquer sleepiness with cognitive performance.

\subsection{Relation between individual differences in the ability to conquer sleepiness during working memory processing and personality traits}

We next explored the relationship between activity in the right prefrontal site corresponding to channel 10 and individual personality traits. We assessed personality traits using the revised version of the Neuroticism-Extroversion-Openness Personality Inventory (NEO PI$\mathrm{R})$ and the Revised Temperament and Character Inventory (TCI, Version 9). NEO PI-R is a 240-item measure of the Five Factor Model: Neuroticism, Extraversion, Openness to experience, Agreeableness, and Conscientiousness (Costa \& McCrae, 1995). The TCI, too, is a 240-item measure of the seven dimensions of personality traits: Novelty seeking, Harm avoidance, Reward dependence, Persistence, Self-directedness, Cooperativeness, and Selftranscendence (Cloninger, 1987). Both of these inventories are widely used in biological correlational research in a variety of fields, including psychiatric diagnosis (Cloninger, 1990; Frokjaer et al., 2008), behavior (Grucza et al., 2006; Saggino \& Balsamo, 2003), genotyping (Cloninger, 2002; Strobel et al., 2003), and brain activities (Baeken et al., 2009; Villafuerte et al., 2011).

We identified several personality traits that correlated with a difference in activity change between the 2- and 0-back tasks at channel 10. For instance, Neuroticism on the NEO PI-R was positively correlated and Self-directedness on the TCI negatively correlated with a difference in change in oxy-Hb concentration between the two tasks (Yoshiike, Honma \& Kuriyama, in preparation). This finding suggests that a stronger tendency for neuroticism and a weaker one for self-directedness may lead to successful performance under sleep loss conditions. Greater neuroticism is sometimes associated with psychiatric problems such as depression or anxiety (Strobel et al., 2003), which reflect poor stress coping mechanisms like avoidance (Andrews et al., 2010). However, within a healthy range, a trait of neuroticism may be beneficial to conquering sleepiness. Moreover, although the concept of selfdirectedness is based on the "power of will" (i.e., the ability to control oneself to serve the purpose of one's own will), greater self-directedness may, surprisingly, result in succumbing to sleepiness. Chronic insomniacs showed greater neuroticism (van de Laar et al., 2010) and less self-directedness (de Saint Hilaire et al., 2005), suggesting that problems in the right PFC might be associated with the symptoms of insomnia.

\section{Conclusion}

When the ROI is compatible with the strengths of NIRS, the technique is valuable for investigating human frontal functioning associated with deteriorated cognition caused by sleep loss. Indeed, our studies demonstrated that certain functional differences in the bilateral PFC under sleep loss conditions correspond to certain cognitive tasks.

We can sum up by saying the PFC mediates various cognitive functions, from basic functions such as simple response to stimulus and time perception to higher functions such as working memory including executive functions, to orchestrate perception, memory, 
thought, and action in accordance with a given purpose (Halford et al., 2010). The findings discussed here clearly suggest a novel function for the PFC, that of controlling sleepiness and compensating brain function deteriorated by sleep loss.

NIRS is a developing technique and it is expected that its applications will increase to cover other cerebral regions in future and that further noise reductions will improve the technique further: it will undoubtedly provide invaluable information about human cognition and its neural substrates.

\section{Acknowledgment}

We are grateful to Kazuo Mishima and Takahiro Soshi for cooperating in our research concerning NIRS.

\section{References}

Andrews, R.M., Browne, A.L., Drummond, P.D., \& Wood, F.M. (2010). The impact of personality and coping on the development of depressive symptoms in adult burns survivors. Burns, Vol.36, No.1, pp. 29-37, ISSN 0305-4179

Aschoff, J. (1998). Human perception of short and long time intervals: its correlation with body temperature and the duration of wake time. Journal of Biological Rhythms, Vol.13, No.5, pp. 437-442, ISSN 0748-7304

Ashoff, J., \& Daan, S. (1997). Human time perception in temporal isolation: effects of illumination intensity. Chronobiology International, Vol.14, No.6, pp. 585-596, ISSN 0742-0528

Baeken, C., De Raedt, R., Ramsey, N., Van Schuerbeek, P., Hermes, D., Bossuyt, A., Leyman, L., Vanderhasselt, M.A., De Mey, J., \& Luypaert, R. (2009). Amygdala responses to positively and negatively valenced baby faces in healthy female volunteers: influences of individual differences in harm avoidance. Brain Research, Vol.3, No.1296, pp. 94-103, ISSN 0006-8993

Bartel, P., Offermeier, W., Smith, F., \& Becker, P. (2004). Attention and working memory in resident anaesthetists after night duty: group and individual effects. Occupational and Environmental Medicine, Vol.61, No.2, pp. 167-170, ISSN 1076-2752

Binks, P.G., Waters, W.F., \& Hurry, M. (1999). Short-term total sleep deprivations does not selectively impair higher cortical functioning. Sleep, Vol.22, No.3, pp. 328-334, ISSN 0161-8105

Blatter, K., Graw, P., Münch, M., Knoblauch, V., Wirz-Justice, A., \& Cajochen, C. (2006). Gender and age differences in psychomotor vigilance performance under differential sleep pressure conditions. Behavioural Brain Research, Vol.168, No.2, pp. 312-317, ISSN 0166-4328

Buysse, D.J., Monk, T.H., Carrier, J., \& Begley, A. (2005). Circadian patterns of sleep, sleepiness, and performance in older and younger adults. Sleep, Vol.28, No.11, pp. 1365-1376, ISSN 0161-8105

Callicott, J.H., Mattay, V.S., Bertolino, A., Finn, K., Coppola, R., Frank, J.A., Goldberg, T.E., \& Weinberger, D.R. (1999). Physiological characteristics of capacity constraints in working memory as revealed by functional MRI. Cerebral Cortex, Vol.9, No.1, pp. 20-26, ISSN 1047-3211 
Callicott, J.H., Ramsey, N.F., Tallent, K., Bertolino, A., Knable, M.B., Coppola, R., Goldberg, T., van Gelderen, P., Mattay, V.S., Frank, J.A., Moonen, C.T., \& Weinberger, D.R. (1998). Functional magnetic resonance imaging brain mapping in psychiatry: methodological issues illustrated in a study of working memory in schizophrenia. Neuropsychopharmacology, Vol.18, No.3, pp. 186-196, ISSN 0893-133X

Choo, W.C., Lee, W.W., Venkatraman, V., Sheu, F.S., \& Chee, M.W. (2005). Dissociation of cortical regions modulated by both working memory load and sleep deprivation and by sleep deprivation alone. Neuroimage, Vol.25, No.2, pp. 579-587, ISSN 10538119

Cloninger, C.R. (1987). A systematic method for clinical description and classification of personality variants. A proposal. Archives of General Psychiatry, Vol.44, No.6, pp. 573-588, ISSN 0003-990X

Cloninger, C.R. (1990). Comorbidity of anxiety and depression. Journal of Clinical Psychopharmacology, Vol.10, No.3, Supplement, pp. 43S-46S, ISSN 0271-0749

Cloninger, C.R. (2002). The discovery of susceptibility genes for mental disorders. Proceedings of the National Academy of Sciences of the United States of America, Vol.99, No.21, pp. 13365-13367, ISSN 0027-8424

Cohen, J.D., Perlstein, W.M., Braver, T.S., Nystrom, L.E., Noll, D.C., Jonides, J., \& Smith, E.E. (1997). Temporal dynamics of brain activation during a working memory task. Nature, Vol.386, No.6625, pp. 604-608, ISSN 0028-0836

Costa, P.T. Jr., \& McCrae, R.R. (1995). Domains and facets: hierarchical personality assessment using the revised NEO personality inventory. Journal of Personality Assessment, Vol.64, No.1, pp. 21-50, ISSN 0022-3891

de Saint Hilaire, Z., Straub, J., \& Pelissolo, A. (2005). Temperament and character in primary insomnia. European Psychiatry, Vol.20, No.2, pp. 188-192, ISSN 0924-9338

Doran, S.M., Van Dongen, H.P., \& Dinges, D.F. (2001). Sustained attention performance during sleep deprivation: evidence of state instability. Archives Italiennes de Biologie, Vol.139, No.3, pp. 253-267, ISSN 0003-9829

Drake, C.L., Roehrs, T.A., Burduvali, E., Bonahoom, A., Rosekind, M., \& Roth, T. (2001). Effects of rapid versus slow accumulation of eight hours of sleep loss. Psychophysiology, Vol.38, No.6, pp. 979-987, ISSN 0048-5772

Drummond, S.P., Paulus, M.P., \& Tapert, S.F. (2006). Effects of two nights sleep deprivation and two nights recovery sleep on response inhibition. Journal of Sleep Research, Vol.15, No.3, pp. 261-265, ISSN 0962-1105

Duncan, J. (2001). An adaptive coding model of neural function in prefrontal cortex. Nature Reviews Neuroscience, Vol.2, No.11, pp. 820-829, ISSN 1471-003X

Ferrari, M., Mottola, L., \& Quaresima, V. (2004). Principles, techniques, and limitations of near infrared spectroscopy. Canadian Journal of Applied Physiology, Vol.29, No.4, pp. 463-487, ISSN 8750-7587

Frey, D.J., Badia, P., \& Wright, K.P. Jr. (2004). Inter- and intra-individual variability in performance near the circadian nadir during sleep deprivation. Journal of Sleep Research, Vol.13, No.4, pp. 305-315, ISSN 0962-1105

Frokjaer, V.G., Mortensen, E.L., Nielsen, F.A., Haugbol, S., Pinborg, L.H., Adams, K.H., Svarer, C., Hasselbalch, S.G., Holm, S., Paulson, O.B., \& Knudsen, G.M. (2008). Frontolimbic serotonin $2 \mathrm{~A}$ receptor binding in healthy subjects is associated with 
personality risk factors for affective disorder. Biological Psychiatry, Vol.63, No.6, pp. 569-576, ISSN 0006-3223

Gevins, A., \& Cutillo, B. (1993). Spatiotemporal dynamics of component processes in human working memory. Electroencephalography and Clinical Neurophysiology, Vol.87, No.3, pp. 128-143, ISSN 0013-4694

Grucza, R.A., Cloninger, C.R., Bucholz, K.K., Constantino, J.N., Schuckit, M.I., Dick, D.M., \& Bierut, L.J. (2006). Novelty seeking as a moderator of familial risk for alcohol dependence. Alcoholism, Clinical and Experimental Research, Vol.30, No.7, pp. 11761183, ISSN 0145-6008

Guiou, M., Sheth, S., Nemoto, M., Walker, M., Pouratian, N., Ba, A., \& Toga, A.W. (2005). Cortical spreading depression produces long-term disruption of activity-related changes in cerebral blood volume and neurovascular coupling. Journal of Biomedical Optics, Vol.10, No.1, pp. 11004, ISSN 1083- 3668

Halford, G.S., Wilson, W.H., \& Phillips, S. (2010). Relational knowledge: the foundation of higher cognition. Trends in Cognitive Sciences, Vol.14, No.11, pp. 497-505, ISSN 13646613

Harrington, D.L., Haaland, K.Y., \& Knight, R.T. (1998). Cortical networks underlying mechanisms of time perception. The Journal of Neuroscience, Vol.18, No.3, pp. 10851095, ISSN 0270-6474

Hoddes, E., Dement, W.C., \& Zarcone, V. (1971). The history and use of the Stanford sleepiness scale. Psychophysiology, Vol.9, pp. 150, ISSN 1469-8986

Honma, M., Soshi, T., Kim, Y., \& Kuriyama, K. (2010). Right prefrontal activity reflects the ability to overcome sleepiness during working memory tasks: a functional nearinfrared spectroscopy study. PLoS ONE, Vol.5, No.9, pp. e12923, ISSN 1932-6203.

Hoshi, Y., Kobayashi, N., \& Tamura, M. (2001). Interpretation of near-infrared spectroscopy signals: a study with a newly developed perfused rat brain model. Journal of Applied Physiology, Vol.90, No.5, pp. 1657-1662, ISSN 0021-8987

Ivry, R.B. (1996). The representation of temporal information in perception and motor control. Current Opinion in Neurobiology, Vol.6, No.6, pp. 851-857, ISSN 0959-4388

Killgore, W.D., Kahn-Greene, E.T., Lipizzi, E.L., Newman, R.A., Kamimori, G.H., \& Balkin, T.J. (2008). Sleep deprivation reduces perceived emotional intelligence and constructive thinking skills. Sleep Medicine, Vol.9, No.5, pp. 517-526, ISSN 13899457

Koslowsky, M., \& Babkoff, H. (1992). Meta-analysis of the relationship between total sleep deprivation and performance. Chronobiology International, Vol.9, No.2, pp. 132-136, ISSN 0742-0528

Kuriyama, K., Mishima, K., Suzuki, H., Aritake, S., \& Uchiyama, M. (2008). Sleep accelerates the improvement in working memory performance. The Journal of Neuroscience, Vol.28, No.40, pp. 10145-10150, ISSN 0270-6474

Kuriyama, K., Uchiyama, M., Suzuki, H., Tagaya, H., Ozaki, A., Aritake, S., Kamei, Y., Nishikawa, T., \& Takahashi, K. (2003). Circadian fluctuation of time perception in healthy human subjects. Neuroscience Research, Vol.46, No.1, pp. 23-31, ISSN 01680102

Kuriyama, K., Uchiyama, M., Suzuki, H., Tagaya, H., Ozaki, A., Aritake, S., Shibui, K., Xin, T., Lan, L., Kamei, Y., \& Takahashi, K. (2005). Diurnal fluctuation of time 
perception under 30-h sustained wakefulness. Neuroscience Research, Vol.53, No.2, pp. 123-128, ISSN 0168-0102

Lim, J., \& Dinges, D.F. (2010). A meta-analysis of the impact of short-term sleep deprivation on cognitive variables. Psychological Bulletin, Vol.136, No.3, pp. 375-389, ISSN 00332909

Miller, E.K., \& Cohen, J.D. (2001). An integrative theory of prefrontal cortex function. Annual Review of Neuroscience, Vol.24, pp. 167-202, ISSN 0147-006X

Nilsson, J.P., Söderström, M., Karlsson, A.U., Lekander, M., Akerstedt, T., Lindroth, N.E., \& Axelsson, J. (2005). Less effective executive functioning after one night's sleep deprivation. Journal of Sleep Research, Vol.14, No.1, pp. 1-6, ISSN 0962-1105

Obrig, H., Neufang, M., Wenzel, R., Kohl, M., Steinbrink, J., Einhäupl, K., \& Villringer, A. (2000). Spontaneous low frequency oscillations of cerebral hemodynamics and metabolism in human adults. Neuroimage, Vol.12, No.6, pp. 623-639, ISSN 1053-8119

Owen, A.M., Doyon, J., Petrides, M., \& Evans, A.C. (1996). Planning and spatial working memory: a positron emission tomography study in humans. European Journal of Neuroscience, Vol.8, No.2, pp. 353-364, ISSN 0953-816X

Owen, A.M., Stern, C.E., Look, R.B., Tracey, I., Rosen, B.R., \& Petrides, M. (1998). Functional organization of spatial and nonspatial working memory processing within the human lateral frontal cortex. Proceedings of the National Academy of Sciences of the United States of America, Vol.95, No.13, pp. 7721-7726, ISSN 0027-8424

Pouthas, V., Maquet, P., Garnero, L., Ferrandez, A.M., \& Renault, B. (1999). Neural basis of time estimation: a PET and ERP study. Electroencephalography and Clinical Neurophysiology Supplement, Vol.50, pp. 598-603, ISSN 0424-8155

Rammsayer, T.H. (1999). Neuropharmacological evidence for different timing mechanisms in humans. Quarterly Journal of Experimental Psychology Section B, Vol.52, No.3, pp. 273-286, ISSN 0272-4995

Rasmussen, T., Holstein-Rathlou, N.H., \& Lauritzen, M. (2009). Modeling neuro-vascular coupling in rat cerebellum: characterization of deviations from linearity. Neuroimage, Vol.45, No.1, pp. 96-108, ISSN 1053-8119

Saggino, A., \& Balsamo, M. (2003). Relationship between WAIS-R intelligence and the fivefactor model of personality in a normal elderly sample. Psychological Reports, Vol.92, No.3 (Part 2), pp. 1151-1161, ISSN 0033-2941

Soshi, T., Kuriyama, K., Aritake, S., Enomoto, M., Hida, A., Tamura, M., Kim, Y., \& Mishima, K. (2010). Sleep deprivation influences diurnal variation of human time perception with prefrontal activity change: a functional near-infrared spectroscopy study. PLoS ONE, Vol.5, No.1, pp. e8395, ISSN 1932-6203

Stenuit, P., \& Kerkhofs, M. (2008). Effects of sleep restriction on cognition in women. Biological Psychology, Vo.77, No.1, pp. 81-88, ISSN 0301-0511

Strobel, A., Gutknecht, L., Rothe, C., Reif, A., Mössner, R., Zeng, Y., Brocke, B., \& Lesch, K.P. (2003). Allelic variation in 5-HT1A receptor expression is associated with anxietyand depression-related personality traits. Journal of Neural Transmission, Vol.110, No.12, pp. 1445-1453, ISSN 0300-9564

Sweeney, J.A., Mintun, M.A., Kwee, S., Wiseman, M.B., Brown, D.L., Rosenberg, D.R., \& Carl, J.R. (1996). Positron emission tomography study of voluntary saccadic eye movements and spatial working memory. Journal of Neurophysiology, Vol.75, No.1, pp.454-468, ISSN 0022-3077 
Treisman, M. (1963). Temporal discrimination and the indifference interval. Implications for a model of the 'internal clock'. Psychological Monographs, Vol.77, No.13, pp. 1-31, ISSN 0016-6677

Tucker, A.M., Whitney, P., Belenky, G., Hinson, J.M., \& Van Dongen, H.P. (2010). Effects of sleep deprivation on dissociated components of executive functioning. Sleep, Vol.33, No.1, 47-57, ISSN 0161-8105

van de Laar, M., Verbeek, I., Pevernagie, D., Aldenkamp, A., \& Overeem, S. (2010). The role of personality traits in insomnia. Sleep Medicine Reviews, Vol.14, No.1, pp. 61-68, ISSN 1087-0792

Van Dongen, H.P., Maislin, G., Mullington, J.M., \& Dinges, D.F. (2004). The cumulative cost of additional wakefulness: dose-response effects on neurobehavioral functions and sleep physiology from chronic sleep restriction and total sleep deprivation. Sleep, Vol.26, No.2, pp. 117-126, ISSN 0161-8105

Villafuerte, S., Heitzeg, M.M., Foley, S., Wendy Yau, W.Y., Majczenko, K., Zubieta, J.K., Zucker, R.A., \& Burmeister, M. (2011). Impulsiveness and insula activation during reward anticipation are associated with genetic variants in GABRA2 in a family sample enriched for alcoholism. Molecular Psychiatry, in press, ISSN 1359-4184

Vyazovskiy, V.V., Olcese, U., Hanlon, E.C., Nir, Y., Cirelli, C., \& Tononi, G. (2011). Local sleep in awake rats. Nature, Vol.472, No.7344, pp. 443-447, ISSN 0028-0836

Wimmer, F., Hoffmann, R.F., Bonato, R.A., \& Moffitt, A.R. (1992). The effects of sleep deprivation on divergent thinking and attention processes. Journal of Sleep Research, Vo.1, No.4, pp. 223-230, ISSN 0962-1105 


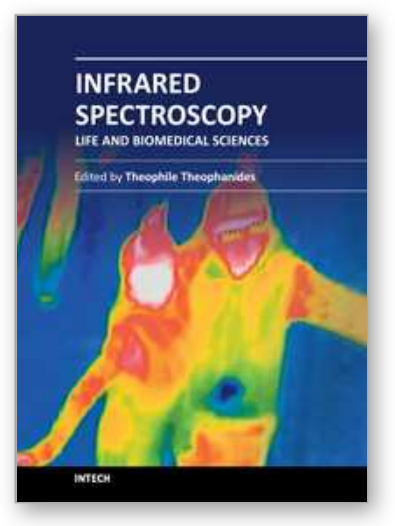

\author{
Infrared Spectroscopy - Life and Biomedical Sciences \\ Edited by Prof. Theophanides Theophile
}

ISBN 978-953-51-0538-1

Hard cover, 368 pages

Publisher InTech

Published online 25, April, 2012

Published in print edition April, 2012

This informative and state-of-the art book on Infrared Spectroscopy in Life sciences designed for researchers, academics as well as for those working in industry, agriculture and in pharmaceutical companies features 20 chapters of applications of MIRS and NIRS in brain activity and clinical research. It shows excellent FT-IR spectra of breast tissues, atheromatic plaques, human bones and projects assessment of haemodynamic activation in the cerebral cortex, brain oxygenation studies and many interesting insights from a medical perspective.

\title{
How to reference
}

In order to correctly reference this scholarly work, feel free to copy and paste the following:

Kenichi Kuriyama and Motoyasu Honma (2012). Effects of Sleep Debt on Cognitive Performance and Prefrontal Activity in Humans, Infrared Spectroscopy - Life and Biomedical Sciences, Prof. Theophanides Theophile (Ed.), ISBN: 978-953-51-0538-1, InTech, Available from: http://www.intechopen.com/books/infraredspectroscopy-life-and-biomedical-sciences/effects-of-sleep-debt-on-cognitive-performance-and-prefrontalactivity-in-humans

\section{INTECH}

open science | open minds

\section{InTech Europe}

University Campus STeP Ri

Slavka Krautzeka 83/A

51000 Rijeka, Croatia

Phone: +385 (51) 770447

Fax: +385 (51) 686166

www.intechopen.com

\section{InTech China}

Unit 405, Office Block, Hotel Equatorial Shanghai

No.65, Yan An Road (West), Shanghai, 200040, China

中国上海市延安西路65号上海国际贵都大饭店办公楼 405 单元

Phone: +86-21-62489820

Fax: $+86-21-62489821$ 
(C) 2012 The Author(s). Licensee IntechOpen. This is an open access article distributed under the terms of the Creative Commons Attribution 3.0 License, which permits unrestricted use, distribution, and reproduction in any medium, provided the original work is properly cited. 